\title{
Review of methods to prevent and reduce the risk of Lyme disease
}

\author{
Lindsay $\mathrm{LR}^{1^{*}}$, Ogden $\mathrm{NH}^{2}$, Schofield $\mathrm{SW}^{3}$ \\ ${ }^{1}$ National Microbiology Laboratory, Public Health Agency of Canada, Winnipeg, MB \\ ${ }^{2}$ Centre for Food-borne, Environmental and Zoonotic Infectious Diseases, Public Health Agency of Canada, Saint-Hyacinthe, \\ $\mathrm{QC}$ \\ ${ }^{3}$ Communicable Disease Control Program, Department of National Defence, Ottawa, ON
}

*Correspondence: robbin.lindsay@phac-aspc.gc.ca

\begin{abstract}
Background: Cases of Lyme disease and areas with self-sustaining populations of vector ticks are increasing in Canada. This trend is expected to continue. Preventing Lyme disease will therefore become relevant to an increasing number of Canadians.
\end{abstract}

Objective: To summarize methods for reducing the risk of tick bites and preventing transmission once a tick is feeding.

Methods: A literature search was conducted to identify methods to reduce the risk of tick bites and the abundance of vector ticks, as well as the risk of becoming infected with the Lyme disease pathogen, Borrelia burgdorferi (BB), if bitten by a vector tick.

Results: Current approaches to reducing the risk of tick bites or preventing infection with BB once bitten are largely reliant on the individual. They include use of topical repellents, use of protective clothing, avoidance of risk areas and removing ticks soon (ideally within a day) after they attach. These methods are efficacious, but constrained by user adherence. Other approaches such as landscape modification or the use of acaricides to control ticks, have shown promise in other countries, but have not been widely adopted in Canada.

Conclusion: Lyme disease will continue to present a threat in Canada. In additional to the existing interventions for prevention of tick bites and Lyme disease, there is a need for new tools to help reduce the risk of Lyme disease to Canadians.

\section{Introduction}

Lyme disease is a serious human illness caused by the bacterium Borrelia burgdorferi (BB). It is transmitted by certain species of Ixodes ticks: the western blacklegged tick (Ixodes pacificus) in some areas west of the Rocky Mountains and the blacklegged tick (Ixodes scapularis) in parts of Canada east of the Rockies. These ticks are infected when they feed on BB-infected wild animal hosts such as rodents and birds. Once infected, they can transmit BB to other animals including humans (1).

Risk of contracting Lyme disease in Canada is highest where populations of blacklegged ticks are established (i.e., when populations are self-sustaining from year to year) (2). Tick occurrence and risk varies on either side of the Rockies. Ixodes pacificus populations are widely established in southern BC. They do not show evidence of expansion and usually have a low BB infection rate $(<5 \%)$. As a result, risk is relatively modest. In contrast, the geographic range of established populations of $I$. scapularis (east of the Rockies) has recently expanded into central and eastern Canada $(2,3)$ and now includes areas near or within urban centers $(4,5)$. Moreover, the proportion of $I$. scapularis infected with BB can be high $(>15 \%)$. The combined effect for some affected areas are more infected ticks, closer to population centers and hence a relatively increased risk for Lyme disease in central and eastern Canada. 
The annual incidence of reported Lyme disease cases has increased markedly in Canada. For example, in 2004 there were only 40 reported cases, however by 2012, there were 338 reported cases (2). Given that the vector range expansion trend is predicted to continue $(2,4)$, the need for effective interventions to prevent tick bites and Lyme disease is becoming increasingly important.

Unfortunately, there are relatively few options available for Canadians to prevent Lyme disease. There is no vaccine for human use (however, there are effective treatments for Lyme disease); tick-killing acaricides are not widely available or used (6); and professional expertise/infrastructure for tick management is limited.

Consequently, prevention relies on measures undertaken by the individual - usually by preventing bites and/or by removing attached ticks before transmission of $\mathrm{BB}$ occurs $(7,8,9,10,11)$. The purpose of this review is to summarize the methods that individuals can use to prevent and manage tick bites to prevent or reduce the risk of Lyme disease. Emphasis is on approaches targeting I. scapularis, but recommendations are generally applicable to I.pacificus and other tick species.

\section{Methods}

A literature search was conducted focussing on measures used to prevent and/or control ticks and their bites. Open source databases (e.g., PubMed, The United States Armed Forces Pest Management Board Literature Retrieval System (http://www.afpmb.org/content/welcome-literature-retrieval-system) were searched for relevant publications using the search terms: "tick" and "repellent"; "Lyme disease" and "prevention"; or, "Ixodes scapularis" and "control". Studies, reviews or reports of interventions or measures were reviewed that had evidence of efficacy, were adopted in other countries and had biologic plausibility that they would reduce risk. The findings were summarized in a narrative review and used to develop the following guidance and recommendations on Lyme disease prevention for Canadians.

\section{Results}

Reports were summarized regarding four prevention methods: avoidance of risk areas; use of protective clothing and prompt tick removal; use of chemical barriers/repellents; and reducing tick abundance in the environment.

\section{Prevent Lyme disease by avoiding areas of risk}

A simple rule for Lyme disease is: if you don't get 'ticked', you don't get sick. Until recently, at least in Canada, this could be achieved by avoiding the few areas where Lyme disease occurred $(12,13)$. However, with the spread of I. scapularis and Lyme disease, vector ticks can be found in many more areas including near to and within densely populated centers and even on residential properties (3). Nevertheless, avoidance remains a viable riskreduction approach (10).

Ticks are associated with specific habitats $(14,15)$ particularly in and around woodland areas (Figure 1) that support populations of rodents, birds and deer which are the main hosts for blacklegged ticks (16). In such areas, ticks are often found in leaf litter at edges (ecotone) of forested habitats, which include hiking or animal trails (16). Indeed, they can thrive in small patches of woodland, including those found in backyards, but are rarely found on lawns, especially those kept short $(17,18,19)$. Thus, if woodland and ecotonal habitats can be avoided, the risk of tick bites is generally very low (20). Conversely, visiting such habitats increases exposure and should prompt consideration of use of additional protective measures, such as repellents (Section 2 below). 
Figure 1: Typical habitat that would support blacklegged tick populations and where blacklegged ticks might be encountered

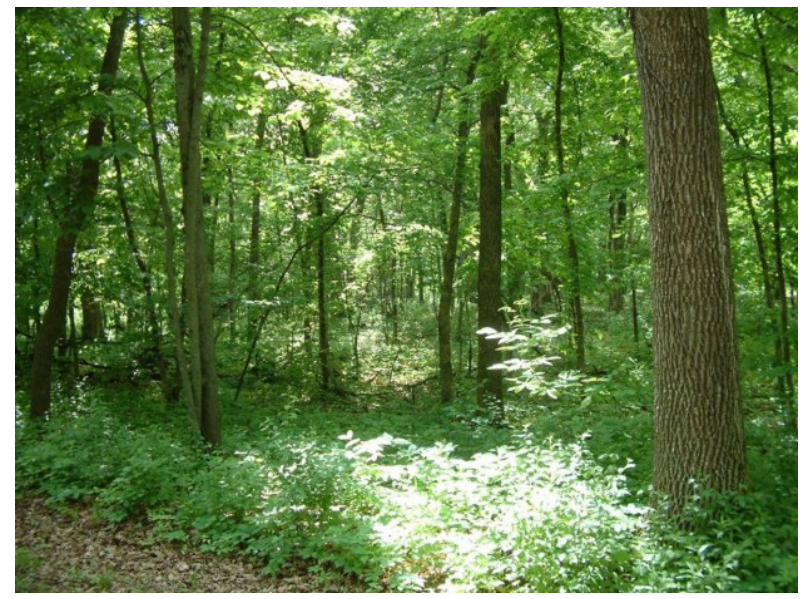

Ticks are associated with specific geographic regions and risk of tick bites and Lyme disease is highest in areas where tick populations are established and self-sustaining. Tick bites and Lyme disease can however, occur in areas where established tick populations are unknown, either because surveillance has yet to identify the population, or because small numbers of 'adventitious' ticks (ticks spread out of established populations by migrating birds) are present $(2,3,13,21)$. Thus, avoiding areas where tick populations are known to be established will reduce but may not eliminate risk.

Risk of Lyme disease also varies with the stage of the tick and by season. Larval ticks (youngest stage) may occasionally bite people but, as they are not infected with BB (22), they are not a threat for Lyme disease although they can occasionally be infected with other pathogens. In Canada, risk is highest in the spring and summer (May through August) when nymphs (the juvenile stage of ticks that have developed from fed larvae preceding adulthood) are active $(23,24)$. The increased risk associated with nymphs likely represents their relatively higher abundance (compared to adults), as well as our reduced efficiency at finding and removing this smaller life stage before transmission occurs (25). Risk also exists earlier in the spring as well as into the autumn when adult ticks are most active (26) and theoretically in the winter if temperatures are above freezing and snow is not on the ground $(16,27)$. Using personal protective measures or avoiding risk areas during the times of year that nymphal and adult ticks are active will significantly reduce or eliminate exposure (28).

\section{Prevent Lyme disease by dressing appropriately and by removing attached ticks}

Individuals who work outdoors or participate in outdoor activities such as golfing, hunting, camping, fishing and hiking may not be able to avoid tick habitats, but they can reduce their risk of contracting Lyme disease. Interventions include dressing appropriately and the removal of attached ticks as soon as possible.

Blacklegged ticks typically wait for a passing host in leaf litter or on vegetation such as low shrubs. From this perch, they grasp onto hosts as they pass and then crawl around to find a place to feed $(16,29)$. Wearing appropriate clothing such as closed-toe shoes, long shirts tucked into trousers and socks pulled over pant legs, limits access to skin, thereby protecting against bites (30). Further, tucked in clothing forces the ticks to travel longer distances on outer garments to find open skin, which should increase the probability that they will be seen and removed before they feed. Wearing light coloured clothing also makes it easier to notice and find ticks (31). To kill any ticks that remain on clothing after use, put garments through a high heat dry cycle if possible (32), then wash and dry again.

Vector ticks feed on their human hosts for up to seven days (16). It has been well established in animal models that most cases of BB transmission does not occur until a day or more after ticks begin to feed $(33,34,35)$. Therefore, removal of ticks within 24 to 36 hours should prevent infection with $B$. burgdorferi in most cases. Indeed, there is evidence that daily checks of one's body for ticks and bathing/showering within a few hours after 
outdoor activity (which increases the chances of finding ticks) reduces the risk of Lyme disease (36). Usually, a tick check should be done after leaving a risk area, although it is also prudent to check for ticks that might be moving over clothing or skin while in tick habitats.

Removal is best done with medium-tipped, stiff and angled forceps (tweezers) placed around the head of the tick as near as possible to the skin, followed by an upward pulling movement $(34,37,38,39)$ as shown in Figure 2. After the tick is removed, the bite site should be cleaned with soap and water and/or treated with an antiseptic.

\section{Figure 2: Diagram depicting the preferred method for removal of attached ticks}

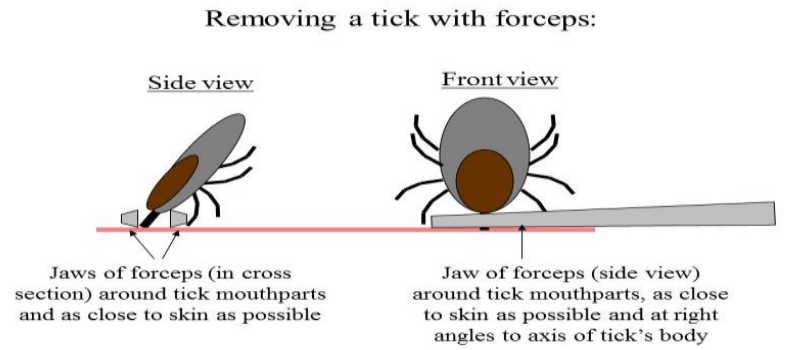

\section{Prevent Lyme disease by using chemical barriers}

Topical repellents can prevent the bites of a wide variety of insect vectors, including ticks $(40,41)$. In Canada, the most widely available repellent is $\mathrm{N}, \mathrm{N}$-diethyl-m-toluamide (DEET). It protects against tick bites, has been reviewed for safety by Health Canada and is a preferred active ingredient for protection against a range of other insect-transmitted pathogens $(40,42,43)$. Generally, products that contain higher concentrations of DEET (e.g., 20 to $30 \%$ ) provide longer periods of protection (44).

These higher concentration products are registered for use on adults and children over the age of 12 . Children between the ages of two and 12 can use products that contain up to $10 \%$ DEET, but no more than three times daily. For children aged from six to 24 months, concentrations of up to $10 \%$ DEET can be used, but only once per day $(44,45)$.

Recently, repellents containing an ingredient called Icaridin, which provides levels and periods of protection similar to DEET, have become available in Canada (46). Icaridin (also called Picaridin and KBR 3023) has been used in other countries for some time, is recommended for protection against the bites of ticks $(40,43)$ and, in contrast to DEET, use of higher concentrations (e.g., 20\%) is not limited by age

(http://publications.gc.ca/collections/collection_2011/sc-hc/H113-9-2011-10-eng.pdf). Thus, if longer protection periods are needed for children, Icaridin might be the preferred repellent. At the time of writing, Icaridin-containing products were not widely available in retail outlets in Canada. However, several companies are planning to market products (including those that contain $20 \%$ Icaridin) across the country in the near future (i.e., spring/summer 2015). For all topical repellents, it is important to read and follow all label directions.

Other insecticides such as permethrin,when impregnated into clothing, also act as a personal protective measure against tick bites $(47,48)$. A recent randomized control trial (RCT) study of persons at high risk of tick exposure demonstrated substantial protection (>90\%) compared to subjects using standard tick bite prevention measures (49).

Permethrin is not currently available to the general public in Canada but it is recommended that Canadians travelling to highly endemic areas of the US (40) and elsewhere (e.g., in Europe) apply permethrin treatments to their clothing or use clothing pre-treated with permethrin. These products can often be obtained in some travel clinics or from outdoors retailers when in the US (40). 
Products that contain permethrin or other active ingredients that are not specifically approved for treatment of clothing to prevent tick bites must not be used for this purpose, as they have not been designed for such use. They may not work and/or pose a health risk if so used.

\section{Prevent Lyme disease by reducing the number of ticks in the environment}

Approaches such as landscape design and management or pesticide application have shown some success in reducing contact between ticks and people in the US and may have a role in Canada.

Simple landscape modifications such as thinning trees and shrubs can reduce an area's suitability for ticks. Tick 'unfriendly' zones can also be created around yards and leisure areas by integrating landscape structures (e.g., a raised deck) and management practices (e.g., grass cutting and scrub removal) (50). For people living in areas where ticks occur, fencing (eight to ten feet high) to keep the deer off their properties reduces Lyme disease risk (36).

Pesticides applied on vegetation in areas where ticks occur, such as in transition areas between woodlands and lawns, can substantially reduce tick populations $(9,51,52)$. This approach has not been widely used in Canada, perhaps because Lyme disease is a 'new' problem and a market has not yet developed. Alternatively, it might reflect concern about pesticide safety or cost (53). Moving forward, individuals, organizations and municipalities will need to balance the use of pesticides to control ticks against cost, benefit and existing and future regulations and legislation related to pesticide application.

Treatment of deer (the main hosts for adult ticks) and rodents (the main reservoirs of the pathogen that carry Lyme disease) with acaricides to kill ticks have shown efficacy in proof-of-principle studies $(54,55)$. However, there is little evidence that deer culls are effective in reducing tick abundance except in unique environmental settings such as on islands (56).

\section{Conclusion}

Over the last few years, Lyme disease in Canada has evolved from an unusual and focal issue, to an emergent and expanding problem. Increasingly, ticks and hence the risk of Lyme disease is encroaching into populated areas. This trend is expected to continue, and as a result, more Canadians will be at increased risk of exposure to tick bites and Lyme disease. Apart from landscape modification to reduce environmental risk, tools to prevent bites and BB infection are largely limited to personal approaches such as the use of repellents and tick checks. While evidence supports the effectiveness of these interventions (although assessment of the degree of effect and quality of evidence awaits systematic reviews), effectiveness is constrained by low levels of adherence (57, 58, 59). Continued efforts to inform Canadians about the risk of Lyme disease and to encourage them to protect themselves against bites and disease are warranted. However, new tools and approaches are also needed, in particular those that complement existing strategies. These may include novel approaches that encourage the use of existing methods and enhance public adherence to recommended personal protection methods; broader use of existing and/or novel methods to control ticks (or BB in ticks and animal reservoirs); development and use of efficacious and publically-acceptable human vaccines; and continuous improvements to risk assessment and forecasting tools. 


\section{Summary of recommendations}

\begin{tabular}{|l|l|l|}
\hline \multicolumn{1}{|c|}{ Strategy/Method } & \multicolumn{1}{|c|}{ Rationale for use } & \multicolumn{1}{|c|}{$\begin{array}{c}\text { Selected } \\
\text { References }\end{array}$} \\
\hline $\begin{array}{l}\text { Use approved and topical repellents (DEET or } \\
\text { lcaridin) on skin (follow label directions) and wear } \\
\text { insecticide-treated clothing (where permitted). }\end{array}$ & $\begin{array}{l}\text { Prevents ticks from biting; some products can kill } \\
\text { ticks. }\end{array}$ & (40, 42, 60) \\
\hline $\begin{array}{l}\text { Perform tick checks at least once a day and } \\
\text { remove any ticks that are found. }\end{array}$ & $\begin{array}{l}\text { Removes tick before transmission of the Lyme } \\
\text { disease pathogen can occur. }\end{array}$ & (38, 61) \\
\hline Avoid tick infested habitats. & Prevents exposure to ticks. & $(10,62)$ \\
\hline $\begin{array}{l}\text { Bath or shower within 2 hours after leaving tick } \\
\text { habitat. }\end{array}$ & $\begin{array}{l}\text { May dislodge unattached ticks and provides } \\
\text { additional opportunity to find/remove attached } \\
\text { ticks. }\end{array}$ & (36) \\
\hline $\begin{array}{l}\text { Wear appropriate clothing, e.g., light-coloured and } \\
\text { long sleeve shirts, socks and full trousers. }\end{array}$ & $\begin{array}{l}\text { Limits or delays access by ticks to sites for } \\
\text { attachment and improves ability to detect (and } \\
\text { remove) unattached ticks on clothing. }\end{array}$ & (30) \\
\hline $\begin{array}{l}\text { Modify yards to reduce tick-bite risk: Fence yards } \\
\text { (8+ feet high), thin trees and shrubs in play areas, } \\
\text { create 'tick unfriendly' zones at the edges of play } \\
\text { areas. }\end{array}$ & $\begin{array}{l}\text { Reduces entry of tick hosts into yards and } \\
\text { reduces number of ticks in play areas by } \\
\text { reducing their survival. }\end{array}$ & (36,50) \\
\hline
\end{tabular}

\section{Acknowledgements}

The authors thank the Pest Management Advisory Committee of the Department of National Defence for providing an unpublished assessment on the efficacy of Icaridin as a tick (and mosquito) repellent.

\section{Conflict of interest}

None

\section{References}

(1) Ogden NH, Lindsay LR, Morshed M, Sockett PN, Artsob H. The emergence of Lyme disease in Canada. CMAJ. 2009;180(12):1221-4.

(2) Ogden NH, Koffi JK, Pelcat Y, Lindsay LR. Environmental risk from Lyme disease in central and eastern Canada: a summary of recent surveillance information. Can Commun Dis Rep. 2014;40-5:74-82.

(3) Ogden NH, Koffi JK, Lindsay LR. Assessment of a screening test to identify Lyme disease risk. Can Commun Dis Rep. 2014;40-5:83-7.

(4) Ogden $\mathrm{NH}$, Lindsay LR, Leighton PA. Predicting the rate of invasion of the agent of Lyme disease Borrelia burgdorferi. J Appl Ecol. 2013;50(2):510-8.

(5) Leighton PA, Koffi JK, Pelcat Y, Lindsay LR, Ogden NH. Predicting the speed of tick invasion: An empirical model of range expansion for the Lyme disease vector Ixodes scapularis in Canada. J Appl Ecol. 2012;49(2):457-64.

(6) Poland GA. Vaccines against Lyme disease: What happened and what lessons can we learn? Clin Infect Dis. 2011 February 01;52(suppl 3):s253-8.

(7) Poland GA. Prevention of Lyme disease: A review of the evidence. Mayo Clin Proc. 2001 Jul;76(7):713-24.

(8) Corapi KM, White MI, Phillips CB, Daltroy LH, Shadick NA, Liang MH. Strategies for primary and secondary prevention of Lyme disease. Nat Clin Pract Rheumatol. 2007 Jan;3(1):20-5.

(9) Hayes EB, Maupin GO, Mount GA, Piesman J. Assessing the prevention effectiveness of local Lyme disease control. J Public Health Manag Pract. 1999;5(3):84-92.

(10) Piesman J, Eisen L. Prevention of tick-borne diseases. Annu Rev Entomol. 2008;53:323-43.

(11) Piesman J, Beard CB. Prevention of tick-borne diseases. J Environ Health. 2012;74(10):30-2.

(12) Ogden NH, Lindsay LR, Morshed M. The emergence of Lyme disease in Canada. CMAJ. 2009;181(5):291.

(13) Ogden NH, Trudel L, Artsob H, Barker IK, Beauchamp G, Charron DF, et al. Ixodes scapularis ticks collected by passive surveillance in Canada: Analysis of geographic distribution and infection with Lyme borreliosis agent Borrelia burgdorferi. J Med Entomol. 2006;43(3):600-9.

(14) Guerra M, Walker E, Jones C, Paskewitz S, Cortinas MR, Stancil A, et al. Predicting the risk of Lyme disease: Habitat suitability for Ixodes scapularis in the north central United States. Emerg Infect Dis. 2002 Mar;8(3):289-97. 
(15) Lindsay LR, Mathison SW, Barker IK, McEwen SA, Surgeoner GA. Abundance of Ixodes scapularis (Acari: Ixodidae) larvae and nymphs in relation to host density and habitat on Long Point, Ontario. J Med Entomol. 1999;36(3):243-54.

(16) Smith RP. Ticks: The vectors of Lyme disease. In: Halperin JJ, editor. Lyme disease: An evidence-based approach.
Wallingford, Oxfordshire, UK: CABI; 2011. p. 1-28.

(16) Smith RP. Ticks: The vectors of Lyme disease. In: Halperin JJ, editor. Lyme disease: An evidence-based approach.
Wallingford, Oxfordshire, UK: CABI; 2011. p. 1-28.

(17) Duffy DC, Clark DD, Campbell SR, Gurney S, Perello R, Simon N. Landscape patterns of abundance of Ixodes scapularis (Acari: Ixodidae) on Shelter Island, New York. J Med Entomol. 1994 Nov;31(6):875-9.

(18) Carroll MC, Ginsberg HS, Hyland KE, Hu R. Distribution of Ixodes dammini (Acari: Ixodidae) in residential lawns on Prudence Island, Rhode Island. J Med Entomol. 1992 Nov;29(6):1052-5.

(19) Maupin GO, Fish D, Zultowsky J, Campos EG, Piesman J. Landscape ecology of Lyme disease in a residential area of Westchester County, New York. Am J Epidemiol. 1991;133(11):1105-13.

(20) Piesman J, Humair P. The spirochetes and vector ticks of Lyme borreliosis in nature. In: Lyme Borreliosis in Europe and North American: Epidemiology and clinical practice. Hoboken, N.J.: John Wiley \& Sons, Inc.; 2011. p. $37-51$.

(21) Diuk-Wasser MA, Hoen AG, Cislo P, Brinkerhoff R, Hamer SA, Rowland M, et al. Human risk of infection with Borrelia burgdorferi, the Lyme disease agent, in eastern United States. Am J Trop Med Hyg. 2012 Feb;86(2):320-7.

(22) Rollend L, Fish D, Childs JE. Transovarial transmission of Borrelia spirochetes by Ixodes scapularis: A summary of the literature and recent observations. Ticks Tick Borne Dis. 2013;4(1-2):46-51.

(23) Bacon RM, Kugeler KJ, Mead PS. Centers for Disease Control and Prevention (CDC). Surveillance for Lyme disease-United States, 1992-2006. MMWR Surveill Summ. 2008 Oct 3;57(10):1-9.

(24) Rodgers SE, Miller NJ, Mather TN. Seasonal variation in nymphal blacklegged tick abundance in southern New England forests. J Med Entomol. 2007 Sep;44(5):898-900.

(25) Falco RC, Fish D, Piesman J. Duration of tick bites in a Lyme disease-endemic area. Am J Epidemiol. 1996 Jan 15;143(2):187-92.

(26) Lindsay LR, Mathison SW, Barker IK, McEwen SA, Gillespie TJ, Surgeoner GA. Microclimate and habitat in relation to Ixodes scapularis (Acari: Ixodidae) populations on Long Point, Ontario, Canada. J Med Entomol. 1999;36(3):25562.

(27) Duffy DC, Campbell SR. Ambient air temperature as a predictor of activity of adult Ixodes scapularis (Acari: Ixodidae). J Med Entomol. 1994 Jan;31(1):178-80.

(28) Clark RP, Hu LT. Prevention of Lyme disease and other tick-borne infections. Infect Dis Clin North Am. 2008;22(3):381-96.

(29) Williams SC, Ward JS. Effects of Japanese barberry (Ranunculales: Berberidaceae) removal and resulting microclimatic changes on Ixodes scapularis (Acari: Ixodidae) abundances in Connecticut, USA. Environ Entomol. 2010 Dec;39(6):1911-21.

(30) Carroll JF, Kramer M. Different activities and footwear influence exposure to host-seeking nymphs of Ixodes scapularis and Amblyomma americanum (Acari: Ixodidae). J Med Entomol. 2001 Jul;38(4):596-600.

(31) Stjernberg L, Berglund J. Detecting ticks on light versus dark clothing. Scand J Infect Dis. 2005;37(5):361-4.

(32) Carroll JF. A cautionary note: Survival of nymphs of two species of ticks (Acari: Ixodidae) among clothes laundered in an automatic washer. J Med Entomol. 2003 Sep;40(5):732-6.

(33) Hojgaard A, Eisen RJ, Piesman J. Transmission dynamics of Borrelia burgdorferi s.s. during the key third day of feeding by nymphal Ixodes scapularis (Acari: Ixodidae). J Med Entomol. 2008 Jul;45(4):732-6.

(34) Piesman J, Dolan MC. Protection against Lyme disease spirochete transmission provided by prompt removal of nymphal Ixodes scapularis (Acari: Ixodidae). J Med Entomol. 2002 May;39(3):509-12.

(35) Piesman J, Mather TN, Sinsky RJ, Spielman A. Duration of tick attachment and Borrelia burgdorferi transmission. J Clin Microbiol. 1987 Mar;25(3):557-8.

(36) Connally NP, Durante AJ, Yousey-Hindes KM, Meek JI, Nelson RS, Heimer R. Peridomestic Lyme disease prevention. Results of a population-based case-control study. Am J Prev Med. 2009;37(3):201-6.

(37) Needham GR. Evaluation of five popular methods for tick removal. Pediatrics. 1985 Jun;75(6):997-1002.

(38) Prevention of Lyme borreliosis. In: Sood SK, editor. Lyme borreliosis in Europe and North America: Epidemiology and clinical practice. Hoboken, N.J.: John Wiley \& Sons, Inc.; 2011. p. 225-44.

(39) Duscher GG, Peschke R, Tichy A. Mechanical tools for the removal of Ixodes ricinus female ticks: Differences of instruments and pulling or twisting? Parasitol Res. 2012 Oct;111(4):1505-11.

(40) Schofield S, Plourde P. Statement on personal protective measures to prevent arthropod bites . An Advisory Committee Statement (ACS). Can Commun Dis Rep. 2012 Nov 2012;38(ACS-3):1-18.

(41) Vázquez M, Muehlenbein C, Cartter M, Hayes EB, Ertel S, Shapiro ED. Effectiveness of personal protective measures to prevent Lyme disease. Emerg Infect Dis. 2008;14(2):210-6.

(42) Katz TM, Miller JH, Hebert AA. Insect repellents: Historical perspectives and new developments. J Am Acad Dermatol. 2008 May;58(5):865-71.

(43) Centre for Disease Control. Preventing tick bites. Atlanta, GA: Centers for Disease Control and Prevention; 2015. http://www.cdc.gov/lyme/prev/index.html.

(44) Health Canada. ARCHIVED - Memo - DEET (N,N-diethyl-m-toluamide) Statement of Guarantee and Labelling Allowances. PMRA; 2010. http://www.hc-sc.gc.ca/cps-spc/pest/registrant-titulaire/prod/_memo-note/deet-eng.php.

(45) Health Canada [Internet]. Insect Repellents. PMRA; 2014 http://www.healthycanadians.gc.ca/environmentenvironnement/pesticides/insect_repellents-insectifuges-eng.php. 
(46) Health Canada [Internet]. Registration Decision RD2012-05, Icaridin.PMRA; 2012. http://www.hc-sc.gc.ca/cpsspc/pubs/pest/_decisions/rd2012-05/index-eng.php.

(47) Miller NJ, Rainone EE, Dyer MC, González ML, Mather TN. Tick bite protection with permethrin-treated summerweight clothing. J Med Entomol. 2011;48(2):327-33.

(48) Evans SR, Korch GW, Lawson MA. Comparative field evaluation of permethrin and deet-treated military uniforms for personal protection against ticks (Acari). J Med Entomol. 1990 Sep;27(5):829-34.

(49) Vaughn MF, Meshnick SR. Pilot study assessing the effectiveness of long-lasting permethrin-impregnated clothing for the prevention of tick bites. Vector Borne Zoonotic Dis. 2011 Jul;11(7):869-75.

(50) Stafford KC. Tick management handbook: An integrated guide for homeowners, pest control operators and public health officials for the prevention of tick-associated disease. New Haven, Conn.: Connecticut Agricultural Experiment Station; 2007.

(51) Schulze TL, Jordan RA, Hung RW, Taylor RC, Markowski D, Chomsky MS. Efficacy of granular deltamethrin against Ixodes scapularis and Amblyomma americanum (Acari: Ixodidade) nymphs. J Med Entomol. 2001 Mar;38(2):344-6.

(52) Schulze TL, Jordan RA, Krivenko AJ. Effects of barrier application of granular deltamethrin on subadult Ixodes scapularis (Acari: Ixodidae) and nontarget forest floor arthropods. J Econ Entomol. 2005 Jun;98(3):976-81.

(53) Gould LH, Nelson RS, Griffith KS, Hayes EB, Piesman J, Mead PS, et al. Knowledge, attitudes and behaviors regarding Lyme disease prevention among Connecticut residents, 1999-2004. Vector Borne Zoonotic Dis. 2008;8(6):769-76.

(54) Dolan MC, Maupin GO, Schneider BS, Denatale C, Hamon N, Cole C, et al. Control of immature Ixodes scapularis (Acari: Ixodidae) on rodent reservoirs of Borrelia burgdorferi in a residential community of southeastern Connecticut. $\mathrm{J}$ Med Entomol. 2004 Nov;41(6):1043-54.

(55) Brei B, Brownstein JS, George JE, Pound JM, Miller JA, Daniels TJ, et al. Evaluation of the United States Department Of Agriculture Northeast Area-wide Tick Control Project by meta-analysis. Vector Borne Zoonotic Dis. 2009 Aug;9(4):423-30.

(56) Rand PW, Lubelczyk C, Holman MS, Lacombe EH, Smith RP. Abundance of Ixodes scapularis (Acari: Ixodidae) after the complete removal of deer from an isolated offshore island, endemic for Lyme Disease. J Med Entomol. 2004 Jul;41(4):779-84.

(57) Bayles BR, Evans G, Allan BF. Knowledge and prevention of tick-borne diseases vary across an urban-to-rural human land-use gradient. Ticks Tick Borne Dis. 2013 Jun;4(4):352-8.

(58) Schofield S, Crane F, Tepper M. Good interventions that few use: Uptake of insect bite precautions in a group of Canadian Forces personnel deployed to Kabul, Afghanistan. Mil Med. 2012;177(2):209-15.

(59) Herrington JE. Risk perceptions regarding ticks and Lyme disease: A national survey. Am J Prev Med. 2004;26(2):135-40.

(60) Bissinger BW, Roe RM. Tick repellents: Past, present, and future. Pestic Biochem Physiol. 2010;96(2):63-79.

(61) Shadick NA, Daltroy LH, Phillips CB, Liang US, Liang MH. Determinants of tick-avoidance behaviors in an endemic area for Lyme disease. Am J Prev Med. 1997 Jul-Aug;13(4):265-70.

(62) Eisen RJ, Piesman J, Zielinski-Gutierrez E, Eisen L. What do we need to know about disease ecology to prevent Lyme disease in the northeastern United States? J Med Entomol. 2012;49(1):11-22. 